Psychopharmacologia (Berl.) 31, 13-24 (1973)

(C) by Springer-Verlag 1973

\title{
Short-Term Effects of Marijuana Smoking on Cognitive Behavior in Experienced Male Users*
}

\author{
Joseph H. Pearl**, Edward F. Domino, and Phillip Rennick \\ Michigan Neuropsychopharmacology Research Program, Lafayette Clinic, \\ Detroit 48207, and University of Michigan, Ann Arbor, Michigan 48104
}

Received September 20, 1972; Final Version. March 30, 1973

\begin{abstract}
The effects of smoking marijuana on the ability to use abstract concepts was tested in 12 experienced marijuana users. Each subject was tested three times, after smoking prepared $300 \mathrm{mg}$ cigarettes containing either $0,1.5$ or $2.9 \%$ $4^{9}$-THC in different sessions according to a Latin Square design. The same number of whole and/or partial cigarettes was smoked by each subject in each of the three sessions. This was determined for individual subjects by the number of $2.9 \% 4^{9}$. THC marijuana cigarettes that the subject had been willing to smoke in a pre-experimental session up to a maximum of $1200 \mathrm{mg}$. The following tests of concept formation and usage were used: 1, a letter series test; 2 . a word grouping test; 3. a conceptual clustering memory test; 4 . a closure speed test; 5. Witkin's Embedded Figures Test; 6. a size weight illusion test; 7. Luchin's Water Jar Test; 8. Luchin's Hidden Word Test; and 9. an anagram test. Marijuana smoking led to a dose-related impairment on the letter series, word grouping, closure speed, and Embedded Figures test. Performance on the size-weight illusion, Luchin's Water Jar', Luchin's Hidden Word, and the anagram tests were unaffected. Conceptual clustering decreased after marijuana smoking. In most cases only the differences between 0 and $2.9 \% \Delta^{9}$-THC marijuana were statistically significant.
\end{abstract}

Key words: Marijuana - Smoking - Cognitive Behavior.

\section{Introduction}

The present investigation is concerned with the effects of marijuana smoking on concept formation tasks. Although there has been research in this area by others (Morrow, 1944; Weil et al., 1968; Hollister and Gillespie, 1970; and Melges et al., 1970) there has been no systematic assessment of marijuana on concept formation skills, utilizing an interrelated battery of tests specifically designed for this function. The general hypothesis of this study is that marijuana will impair its user's ability to form and use abstract concepts. This is not a new notion. Many eminent authors have suggested such ideas based upon personal or observational experience (Huxley, 1954). This manuscript decribes the results of marijuana smoking on nine measures of seven different concept formation

* This study is a partial report of a Ph. D. dissertation of J. H. P. submitted to the University of Michigan while on a USPHS predoctoral traineeship, NIMH, USPHS 5TOI MH-0667-13. Also supported in part by grant USPHS MH-11846.

** Present address: Department of Educational Psychology, Oklahoma State University, Stillwater, Oklahoma 74074, U.S.A. 
tasks chosen to test this hypothesis. Marijuana of three strengths: 0 , 1.5 and $2.9 \% \Delta^{9}$-tetrahydrocannabinol (THC) was smoked by each subject $(S)$, to allow examination of dose effects.

\section{Methods \\ Subjects}

The $S \mathrm{~s}$ were 12 adult, male, experienced volunteer users of marijuana. The approximate number of times each had used marijuana in the year preceding the experiment, according to the $S \mathrm{~s}^{\prime}$ own estimates, ranged from 3 to 500 .

All $S$ s were respondents to word-of-mouth advertising about the projeet. Each $S$ was paid $\$ 20$ for his participation in the study. The mean age was 25.8 with range of 21 to 33 years. Of the $12 \mathrm{Ss}, 10$ were university students and 2 were employed. All Ss agreed to abstain from use of drugs for at least $24 \mathrm{~h}$ prior to each experimental session.

\section{Tests}

The tests used were chosen to require the $S_{\mathrm{s}}$ to form and use abstract concepts in a variety of ways. They included the following:

1. Letter Series Test. This test was taken from the Science Research Associates Primary Mental Abilities (PMA) Test, Revised, 1962. In each problem of this test, the $S$ was presented with an ordered series of letters. His task was to abstract the pattern underlying the series in order to figure out which letter comes next, e.g., ababab? Scores were recorded for both time and number correct. Ss were allowed a maximum of 120 sec for each problem. Three parallel forms of nine problems each were obtained by randomly dividing twenty problems from the PMA test for grades 9-12 and seven problems from the PMA test for grades 6-9.

2. Word Grouping Test. This test was also taken from the Science Research Associates PMA Test, Revised, 1962. In each problem, the $S$ was presented with a group of five words, four of which belonged to the same conceptual category. He had to abstract the conceptual category in order to determine which word did not belong with the other four. Scores were recorded for both time and number correct. Three parallel forms of ten problems each were obtained by randomly dividing the 30 problems of the PMA test for grades 9-12.

3. Conceptual Clustering Memory Test. In this test, the $S$ was presented with a list of 24 words, one at a time, which he read within $2 \mathrm{~min}$. When he finished he was instructed to recall, and write down, as many of the words as he could, in whatever order they came to him. Each list consisted of six words from each of four conceptual categories, arranged in random order. The $S$ s score was determined by the degree to which he recalled words from the same conceptual categories in adjacent positions. Bousfield (1953) has shown that $S$ s who are presented with this kind of task tend to recall members of the same conceptual category in adjacent positions with greater than chance frequency. In order to make three forms of this test, 12 conceptual categories of approximately similar levels of abstraction were chosen. The categories were: trees, parts of the body, vegetables, animals, countries, weapons, articles of olothing, colors, sports, musical instruments, boys' names, and professions. Next, the categories were randomly divided into three groups of four each. Finally, six words for each category were chosen from the Thorndike and Lorge (1944) word frequency tables in such a way that the mean frequencies of the words in each category were approximately the same.

The measure of conceptual clustering used in this study is the ratio of repetition (RR). The RR was first used by Bousfield (1953), and has since become one of the most commonly used indices of clustering. The $R R=S /(N-1)$, where $S$ is the number 
of sequences in the list of remembered words and $\mathrm{N}$ is the number of words remembered. A sequence occurs any time that two words from the same conceptual category are recalled in adjacent positions. The $R R$ is said to be independent of the number of words actually recalled (Dalrymple-Alford, 1970).

4. Closure Speed Test. This test was adapted from the Closure Speed Test (1966), published by the Industrial Relations Center of the University of Chicago and the Gestalt Completion Test (1962), published by the Educational Testing Service, Princeton, N. J. The $S$ was presented with a series of pictures with parts missing. His task was to identify the pictures as quickly and as accurately as possible. He was given two minutes to identify as many pictures as he could. Three parallel forms of 14 items each were obtained by randomly dividing the 24 items of the Closure Speed Test and the 20 items of the Gestalt Completion Test into three groups of 14 each, subject to the restriction that each of the two original tests be equally represented in each form.

5. Embedded Figures Test. This was an adaptation of the Embedded Figures Test developed by Witkin (1950) and published in 1969 by the Consulting Psychologists Press, Inc. In each item of this test the $S$ was shown a complex design and required to find, as quickly as possible, a simple figure which was embedded within it. He was allowed a maximum of three min on each item. His score was the total amount of time taken to solve all the items, with failures scored as $180 \mathrm{sec}$.

In order to obtain three parallel forms of this test, the 24 items in Witkin's test were divided into three groups of eight items each. The division of the 24 original items was random, subject to the restriction that each group of eight have approximately the same total mean solution time, according to the norms for each item which Witkin published in 1950.

6. Size-Weight Illusion Test (SWI). In this test the $S$ was presented with a series of 29 small-volume cylindrical weights, arranged in a semicircle before him. The cylinders were ordered according to weight. He was then given three larger cylinders, one at a time, and instructed to place each one in the series of small cylinders, in accordance with its weight, so that the small cylinder to its left seemed lighter and the small cylinder to its right seemed heavier. He was scored according to how far away from its true position he placed each large weight, without regard to direction. For example, if a particular large weight ought to go between numbers 22 and 23 , and the $S$ placed it between numbers 17 and 18 , then he received a score of 5 . The score recorded for each $S$ was a total of three such absolute deviation scores, one for each large weight placed. $S$ s presented with this kind of task will almost invariably underestimate the weight of the large cylinders relative to that of the small ones (Werber and King, 1962).

Ss were also asked to place in the series of small weights two cylindrical weights of the same size as those in the series. The scoring procedure was the same as for the large weights. The three forms of this test differed only in the weights of the cylinders to be placed in the ordered sequence.

7. Water-Jar, Hidden World, and Anagram T'ests. These were included as tests of stereotypy or perseveration in solution of problems. The Water-Jar Test was developed by Luchins (1942). The $S$ was presented with a series of problems of the following form: Given three jars, one holding 21 quarts, one 127 quarts, and one 3 quarts and an unlimited supply of water, obtain 100 quarts of water. The first few problems are all solvable by the same formula: $B(127)-A(21)-2 C(6)=$ the correct answer (100). These problems establish a problem-solving set to use this formula. They are followed by a series of critical problems, which may be solved by this formula or by a more direct method. For example, $A=23$ quarts, $B=49$ quarts, $C=3$ quarts, obtain 20 quarts: $\mathrm{B}(49)-\mathrm{A}(23)-2 \mathrm{C}(6)=20$, or $\mathrm{A}(23)-\mathrm{C}(3)=20$. 
The Hidden Word Test was also developed by Luchins (1942). It is structured similarly to the Water-Jar Test, differing only in the nature of the problems solved. In the Hidden Word Test, the S's task was to find a word in a string of letters, without changing the order of the letters. The training problems establish the set of using alternate letters in the list, beginning with the first letter, to find an animal name, e.g., MSAVRAE (solution: MARE). The critical problems can be solved this way, but they also include a more direct solution, a series of consecutive letters which form a word, e.g., TSINGREVR (set solution: TIGER; direct solution: SING).

The Anagram Test was developed by Rees and Israel (1934-1935). It consists of a series of 30 anagrams. The first 15 (training) anagrams are solvable only by a particular rearrangement of the letter order. The second 15 (critical) anagrams are solvable by this pattern, but also include other solutions.

For purposes of analysis, these three tests were treated as parallel forms of the same test. The score recorded for each of the tests was the ratio of the number of direct solutions to the total number of solutions of the critical problems. This variable was used, rather than simply the number of direct solutions, to make the tests comparable and to control for differences in dosage on the total number of critical problems solved.

\section{Experimental Design}

The experimental design used in this study was a three by three Greco-Latin Square. Each $S$ was randomly assigned a number from 1 to 12 to determine his place in the design. The order in which the seven tests were administered was separately randomized for each $S$, subject to the restriction that each test appear approximately the same number of times in each sequential position. Each $S$ experienced the same order of test administration in all three experimental sessions.

This design has a number of desirable characteristics. Since each $S$ experienced every dosage level and every test form, inter-subject variability should not influence the effect of dosage levels. Of the six possible form orders and six possible dosage orders, each one occurred twice. Since each test form occurred an equal number of times within each dosage level (four), differences in the difficulty of the test forms (if there are any) should not be confounded with the effect of dosage levels.

\section{Procedures}

The Marijuana. Both the active and placebo marijuana were obtained from the National Institute of Mental Health for use in this study ${ }^{1}$. The two active grades of marijuana contained 1.5\% $\Delta^{9}$-THC (low dose) and $2.9 \% \Delta^{9}$-THC (high dose). The placebo material consisted of marijuana from which all of the $\Delta^{9}$-THC had been extracted without significant alteration of taste, smell and texture of the material.

Ss smoked the marijuana in cigarettes prepared by the staff pharmacist at the Lafayette Clinic in Detroit, Michigan. The study was approved by the human use committees of both the Lafayette Clinic and the University of Michigan.

Dosage Levels. Prior to the three experimental sessions of this study, each $S$ participated in an experimental session at which his individual dosage level was determined. During this session, the $S$ was instructed to smoke as much $2.9 \%$ $\triangle^{9}$-THC marijuana as he could, to a maximum of four $300 \mathrm{mg}$ cigarettes. The $S$ was encouraged to continue smoking until he actually refused to smoke any more, generally because he felt "too high" in spite of moderate urging by the experimenter. Both the $S$ and the experimenter knew prior to the beginning of this session that

1 Marijuana kindly supplied by Dr. Monique C. Braude, Executive Secretary, Psychotomimetic Agents Advisory Committee, Center for Narcotic and Drug Abuse, Parklawn Building, 5600 Fishers Lane, Rockville, Maryland 20852. 
active marijuana was being used. A variety of other data, mostly physiological in nature, was also collected during the dosage study and will be reported as a separate communication (Domino et al., 1973).

In the following three sessions, each $S$ smoked the same number of cigarettes and or fractions thereof that he had smoked during the first session. For different sessions he smoked only one grade of material, either the "high dose" (2.9\% $\left.\Delta^{9}-\mathrm{THC}\right)$ "low dose" $\left(1.5 \% \Delta^{9}-\mathrm{THC}\right)$, or placebo $\left(0 \% \Delta^{9}-\mathrm{THC}\right)$. After each session the cigarette butts were weighed to determine precisely how much the $S$ had smoked during that session. The appropriate number of cigarettes were placed in envelopes marked only with the $S$ 's number, his name and the session number (1st, 2nd, or 3rd) corresponding to that dosage level in the experimental design.

\section{The Experimental Sessions}

The sequence of events for each of the three experimental sessions was as follows:

\section{Approximate time}

1. $20 \mathrm{~min}$

2. $20-40 \mathrm{~min}$

3. $20 \mathrm{~min}$

4. $40-60 \mathrm{~min}$

5. $20 \mathrm{~min}$
Activity

Pre-smoking neuropsychological tests

Smoking

Post-smoking neuropsychological tests

Abstraction test battery

Final neuropsychological tests

The results of the neuropsychological tests will be reported as a separate communication (Rennick et al., 1973).

The experimental sessions were held in three isolated, sound-quieted testing rooms in the research wing of the Lafayette Clinic. The smoking took place in one room, the neuropsychological tests in another, and the abstraction test battery in the third.

During each session the $S$ 's pulse was taken on at least six occasions. Ss were tested one at a time. During the administration of the cognitive tests, the experimenter sat next to the $S$ at a small table and timed the $S$ 's performance, where appropriate, with a stop watch. The $S$ 's smoking was supervised by the experimenters who sat in the same room, lightly conversing with the $S$ while observing. Ss were asked, immediately after smoking, to judge whether the marijuana they had smoked that evening was "strong", "medium", or "weak". The S's knew that they would be smoking three different strengths of marijuana during the three experimental sessions. They did not know the $\Delta^{9}$-THC content of the three strengths (although most of them seemed to assume that one would be placebo) or the strength used in any particular session. At the conclusion of the last experimental session, each $S$ was given a short questionnaire to fillout the following day and return by mail. The questionnaire asked $S$ s to compare the three experimental sessions with regard to the strength of marijuana they smoked, their performance on the cognitive tests, their motivation to do well, and the time pressure they felt on those cognitive tests which were timed.

The three experimental sessions were generally held at one week intervals, although a few were separated by two or three weeks. Generally, two $S$ s were run each Tuesday and Thursday evening, beginning at about 6:30 P.M. The second $S$ began his pre-smoking neuropsychology segment when the first $S$ began his abstraction battery to allow individual testing of each $S$.

\section{Analysis of Data}

The design allowed repeated measures for each test over the three sessions and dosages. Only the dosage data is reported, as no order effects were noted.

2 Psychopharmacologia (Berl.), Vol. 31 
Table 1. Amount of marijuana smoked by each $S$ in each session (in $\mathrm{mg}$ )

\begin{tabular}{lccccc}
\hline$S$ No. & 1st Session & 2nd Session & 3rd Session & Sum & Mean \\
\hline 1 & 591.8 & 587.8 & 595.0 & 1774.6 & 591.5 \\
2 & 787.5 & 640.8 & 587.1 & 2015.4 & 671.8 \\
3 & 815.5 & 964.0 & 1011.9 & 2791.4 & 930.5 \\
4 & 566.6 & 562.0 & 596.9 & 1725.5 & 575.2 \\
5 & 492.5 & 476.6 & 337.3 & 1306.4 & 435.5 \\
6 & 586.1 & 685.6 & 660.3 & 1932.0 & 644.0 \\
7 & 1111.4 & 1042.8 & 1055.9 & 3210.1 & 1070.0 \\
8 & 881.5 & 848.8 & 875.0 & 2605.3 & 868.4 \\
9 & 408.8 & 399.4 & 507.3 & 1315.5 & 438.5 \\
10 & 849.8 & 833.0 & 874.6 & 2557.4 & 852.5 \\
11 & 393.4 & 259.3 & 276.2 & 928.9 & 309.6 \\
12 & 1000.0 & 1026.6 & 928.0 & 2954.6 & 984.9 \\
\hline
\end{tabular}

\section{Results}

Subjective Effects of Marijuana Smoking. The amount of marijuana smoked by each subject varied from only slightly over one to all four $300 \mathrm{mg}$ cigarettes and is given in Table 1 for each $S$ and session. Each $S$ was asked to estimate at three different times (just after smoking, just before testing, and just after testing) his subjective "high" on a 0 to 10 scale with 10 being the greatest "high" he ever experienced. The mean high \pm S.D. for all 12 subjects was as follows:

$\begin{array}{llll} & 0.0 \% \Delta^{9}-\mathrm{THC} & 1.5 \% \Delta^{9}-\mathrm{THC} & 2.9 \% \Delta^{9}-\mathrm{THC} \\ \text { After smoking } & 2.2 \pm 1.9 \ldots & 6.3 \pm 2.5 & 8.8 \pm 1.3 \\ \text { Before testing } & 1.5 \pm 1.3 & 6.7 \pm 2.4 & 8.6 \pm 2.0 \\ \text { After testing } & 0.5 \pm 0.8 & 5.0 \pm 2.4 & 7.2 \pm 2.7\end{array}$

It can be seen that there was a dose-related increase in the mean subjective "high." Since the greatest mean "high" was 8.8 , the originalobjective of achieving a maximal "high" of 10 was not completely achieved using $2.9 \% \Delta^{9}$-THC marijuana. Over the one-hour period of testing the subjective "high" dissipated more rapidly for the placebo than active marijuana. Especially with the most potent marijuana, some $S$ s were quite giddy and frivolous when not concentrating on the tests. One vomited, but felt well enough to complete the test series.

\section{Specific Test Findings}

Letter Series Test. Marijuana led to a dose-related impairment in both time and correct answer scores although only the difference in number of correct answers between the placebo and high dose conditions was statistically significant $(P<0.025)$. The mean \pm S.D. for the time scores were: placebo, $162.4 \pm 68.5$; low dose, $210.0 \pm 118.1$; and high dose, 
$224.4 \pm 83.8$ seconds. The mean \pm S.D. for the number right was: placebo, $7.6 \pm 1.3$; low dose, $6.6 \pm 2.3$; and high dose, $5.8 \pm 2.1$.

Word Grouping Test. Marijuana had a dose-related effect in prolonging the time scores. Newman-Keuls tests showed that the differences between placebo and high dose conditions $(P<0.01)$ and between low dose and high dose conditions $(P<0.05)$ were both statistically significant while the difference between placebo and low dose conditions was not. The means \pm S.D. for the time score were: placebo, $115.0 \pm 36.1$; low dose, $139.5 \pm 64.2$; and high dose, $173.3 \pm 61.3 \mathrm{sec}$.

There were only slight differences among the three conditions with regard to number right. The differences were not dose-related, nor were they statistically significant. The means \pm S.D. for the number right were: placebo, $8.3 \pm 1.2$; low dose, $7.7 \pm 2.2$; and high dose, $8.0 \pm 0.9$.

Conceptual Clustering Memory Test. Marijuana had a dose-related reduction in the ratio of repetition. Newman-Keuls tests show that the differences between placebo and high dose conditions $(P<0.01)$ and between placebo and low dose conditions $(P<0.01)$ were both statistically significant, but that the difference between high dose and low dose conditions was not. The means \pm S.D. for the ratio of repetition were: placebo, $0.53 \pm 0.12$; low dose, $0.35 \pm 0.17$; and high dose, $0.29 \pm 0.12$.

Closure Speed Test. Ss correctly identified significantly $(P<0.01)$ fewer Closure Speed pictures in the high dose than in the placebo condition but showed no difference between the low dose and placebo conditions. This same pattern held in the number of items attempted. Ss were correct on $87 \%$ of the items attempted in the placebo and low dose conditions, but on only $74 \%$ of the items attempted in the high dose condition. The means \pm S.D. for the number right were: placebo, $10.3 \pm 1.6$; low dose, $10.3 \pm 1.8$; and high dose, $7.2 \pm 3.6$. The means \pm S.D. for the number attempted were: placebo, $11.8 \pm 2.1$; low dose, $11.8 \pm 2.0 ;$ and high dose, $9.8 \pm 3.1$.

Embedded Figures Test. Marijuana impaired time scores on this test. Newman-Keuls tests showed that only the difference between high dose and placebo conditions was significant $(<0.05)$. The means \pm S.D. for the time scores were: placebo, $225.9 \pm 216.9$; low dose, $339.9 \pm 268.9$; and high dose, $412.7 \pm 361.7 \mathrm{sec}$.

Size-Weight Illusion Test (SWI). Marijuana tended to have a doserelated effect on the magnitude of the size-weight illusion but it was not statistically significant. Means \pm S.D. of the sum of absolute deviations were: placebo, $48.8 \pm 6.1$; low dose, $45.0 \pm 10.9$; and high dose, $42.5 \pm 14.2$.

Water-Jar, Hidden Word, and Anagram Tests. The differences among dosage levels of marijuana were neither dose-related nor statistically 
significant. The means \pm S.D. of the ratio of the direct critical/total critical solutions were: placebo, $0.48 \pm 0.34$; low dose, $0.29 \pm 0.28$; and high dose, $0.32 \pm 0.32$.

\section{General Findings}

Variability of Performance. Clark et al. (1970) concluded that "... in the dose given the principal effect of marijuana on reaction time occurs through sporadic impairment of the subject's capacity to maintain response set ( $p .197)$." If this sporadic impairment in response set is a general effect of marijuana intoxication, and not specific to reaction time tests like those used by Clark and his associates, then it should be reflected in the variability within a $S$ 's scores on a series of similar test items, such as those which make up the Letter Series Test and the Embedded Figures Test. Since the items in these tests were timed individually, it was possible to compute a standard deviation for each $S$ on each test which would reflect such variability. The means $\pm S . D$. of the standard deviations for the Letter Series test were: placebo, 11.4 \pm 7.3 ; low dose, $15.7 \pm 10.9$; and high dose, $15.4 \pm 8.4$. The means of the standard deviations for the Embedded Figures Tests were: placebo, $28.2 \pm 24.2$; low dose, $41.1 \pm 24.8$; and high dose, $40.4 \pm 21.5$. The pattern of results is similar for both tests. Mean S.D.s were considerably higher in the marijuana conditions than in the placebo condition but the differences were not statistically significant, and there was almost no difference between low dose and high dose conditions. Although these results do not definitely support the findings of Clark and his associates, they are consistent with them.

Short-Term Memory. One of the most commonly reported effects of marijuana intoxication is impairment of short-term memory. Two measures of short-term memory were recorded as part of this study: the number of words recalled in the Conceptual Clustering Memory Test and the number of reviews (requests to see the simple figure again) in the Embedded Figures Test.

Marijuana clearly had a detrimental, dose-related effect on the number of words recalled in the Conceptual Clustering Memory Test. Newman-Keuls tests show that the differences between high dose and placebo conditions $(p<0.01)$ and between low dose and placebo conditions $(p<0.01)$ were both significant, although the difference between high dose and low dose conditions was not. The mean \pm S.D. number of words recalled in each dosage conditions was: placebo, $13.4 \pm 3.4$; low dose, $9.8 \pm 3.5$; and high dose, $8.5 \pm 3.4$.

The effect of marijuana on number of reviews in the Embedded Figures Test was unclear. The mean number of reviews was higher in both marijuana conditions than in the placebo condition, but it was 
higher in the low dose than in the high dose condition, and the difference between the high dose and placebo conditions was relatively small. None of the differences were statistically significant. The mean \pm S.D. number of reviews in each dosage condition was: placebo, $1.5 \pm 1.8$; low dose, $2.8 \pm 3.5$; and high dose, $1.8 \pm 1.4$.

Weight-Judging Ability. Sensory acuity has generally been found to be unaffected by marijuana. Results of that part of the size-weight illusion test which measured simple woight-judging ability support this finding. Marijuana had no significant nor dose-related effect on weight-judging ability. The means \pm S.D. for the sum of absolute deviations in placing the small cylinders in the size weight illusion test were: placebo, $6.3 \pm 2.5$ low dose, $5.9 \pm 4.0$; and high dose, $7.2 \pm \mathbf{5 . 6}$.

$S s^{\prime}$ Estimates of Their Own Performance. Each $S$ was asked to rate each test (except the Water-Jar, Hidden Word, and Anagram Tests) with regard to the experimental session in which he felt he did best and worst in that test. Thus, there was a total of 60 test performances to be rated "best" and "worst" (ten $S$ s, six tests each). The results are as follows :

$\begin{array}{lccc} & \text { Best } & \text { Worst } & \text { Don't Know } \\ \text { High dose } & 5 & 37 & \\ \text { Low dose } & 14 & 4 & 13 \\ \text { Placebo } & 28 & 6 & \end{array}$

Substracting the 13 "don't know" responses there are 47 "bests" and "worsts" distributed among the three dosage levels. It is clear that $S$ s generally felt they did worst in the high dose condition and best in the placebo condition. These ratings are consistent with $S \mathrm{~s}^{\prime}$ actual performance, and contradict the notion that marijuana leads one to greatly overestimate his capabilities.

\section{Discussion}

In order to make a realistic interpretation of the results of this study, one must take into account two methodological considerations. To begin with, dosage levels were determined subjectively. Ss did not all smoke the same quantity of marijuana, nor were the amounts they smoked based on their respective body weights. Each $S$ 's dose was individually determined according to his point of refusal during the initial session. Thus, any implications concerning the effects of marijuana drawn from this study cannot include an objective specification of the amount of marijuana which is likely to produce that effect.

There were three reasons for this departure from the traditional objective specification of dosage level. The first was purely practical. It has been the authors' experience that marijuana users have highly individual 
styles of smoking. They vary considerably with regard to length of time between inhalations, amount of smoke taken in during a single inhalation, and amount of time that smoke from a single inhalation is held in the lungs. Efforts to make different $S$ s conform to the same style have been generally unsuccessful. Thus, it appeared that it would be very difficult to attempt to standardize dosage by setting a fixed quantity of marijuana for each $S$ to smoke.

The second reason was more theoretical. If one conceives of a marijuana study as an investigation of the effects of a drug on an organism, then one would certainly want to objectively standardize the amount of the drug consumed by each $\mathrm{S}$. But if one conceives of a marijuana study as an attempt to analyze the marijuana experience as a subjective one, then it is the "intensity" of the experience which should be standardized. In view of the folklore that the intensity of the marijuana experience is not invariably related to the amount smoked (e.g., experienced smokers are said to need less than new smokers to achieve the same subjective effects) it makes a good deal of sense to use a subjective endpoint in determining dosage. This study was, in fact, conceived of as an attempt to analyze the subjective marijuana experience at three different levels of $\Delta^{9}$-THC content.

The third reason had to do with the potential implications of the study. Insofar as one wishes to draw implications from a laboratory study for a real-world situation, it is desirable to reproduce, as closely as possible, the real-world situation in the laboratory. In the real world, marijuana users generally dose themselves subjectively; they keep smoking until they don't want anymore. Thus, it makes sense to use a similar procedure in the laboratory.

Of the seven variables which showed statistically significant differences with respect to dosage level, five of them showed significant differences between the high dose and placebo conditions, but not between the low dose and placebo conditions. Thus dosage level was certainly an important factor in determining the pattern of results obtained in this study. With regard to the implications of this study for the real world, it should be noted that the high dose is probably more than most of the $S_{s}$ would normally smoke. In fact, the importance of dosage level may have been underestimated. There are some indications (casual discussions with $S_{\mathrm{s}}$, etc.) that a few of the $S$ s felt significant anxiety during the first (dosagesetting) session, and attempted to modify their smoking techniques in the later sessions so as to decrease their dosage. Thus, the difference between the low and high dosage of these $S$ s may have been less than intended.

These results clearly indicate that the pattern of marijuana effects demonstrated in a research study may substantially depend upon the dosage level used in the study. The importance of dosage level may help 
explain the general inconsistency of the findings of marijuana research to date. Various studies have used different dosage levels. It is not surprising that they have obtained different results. Even within the present study, the pattern of results one sees by looking only at low dose-placebo comparisons is considerably different than the pattern of results one sees by looking only at high dose-placebo comparisons.

An important methodological consideration has to do with the attempt to make the study double-blind. This was not very successful. Results of the post-study questionnaire indicate that $S$ s were generally aware of which dose was received in each session. Only one $S$ erred in guessing the doses of marijuana he received. He confused the "strongest" and "medium" doses, but guessed the "weakest" dose correctly. In addition, the experimenter could almost always tell whether a $S$ had received placebo or active marijuana, either by the $S$ s behavior or simply by his unsolicited statements that he was or was not "stoned." Discriminations by the experimenter between low dose and high dose conditions could occasionally be made but much less frequently and with less certainty. These results conflict with the report of Jones and Stone (1970) that $S$ s could not distinguish active marijuana from placebo, and support Weil's (1969) contention that it is impossible to do truly doubleblind research on marijuana, using experienced $S \mathrm{~s}$.

In view of the fact that $S$ s could distinguish among different dosage levels on the basis of subjective effects and the experimenter could distinguish among different dosage levels on the basis of the $S$ 's post-drug behavior, there is no reason to expect that this problem would be eliminated by using oral rather than smoked doses of marijuana.

Acknowledgements. The authors would like to thank Dr. James Grisell and Ms. Kathleen Lennox of the Lafayette Clinic Computing Laboratory for programming and statistical analysis, and Dr. Jacques Gottlieb for providing the research facilities.

\section{References}

Bousfield, W. A.: The occurrence of clustering in the recall of randomly arranged associates. J. genet. Psychol. 49, 229-240 (1953).

Clark, L. D., Hughes, R., Nakashima, E. N.: Behavioral effects of marihuana. Arch. gen. Psychiat. 23, 193-199(1970).

Closure Speed Test Administration Manual. Chicago: Industrial Relations Center, University of Chicago, 1966.

Dalrymple-Alford, E. C.: Measurement of clustering in free recall. Psychol. Bull. $74,32-34$ (1970).

Domino, E. F., Rennick, P., Pearl, J.: Some dose-effect relations of marihuana smoking in experienced male users. In preparation (1973).

Embedded Figures Test. Palo Alto: Consulting Psychologists Press, Inc. 1969.

Gestalt Completion Test. Princeton: Educational Testing Service 1962.

Hollister, L. E., Gillespie, H. K.: Marihuana, ethanol and dextroamphetamine. Arch, gen. Psychiat. 23, 199-203 (1970). 
Huxley, A.: The Doors of Perception. New York: Harper Colophon Books 1954, republished 1963.

Jones, R. T., Stone, G. C.: Psychological studies of marijuana and alcohol in man. Psychopharmacologia (Berl.) 18, 108-117 (1970).

Luchins, A. S.: Mechanization in problem solving: The effect of einstellung. Psychol. Monogr. 64, No. 248 (1942).

Melges, F. T., Tinklenberg, J. R., Hollister, L. E., Gillespie, H. K.: Marihuana and temporal disintegration. Science 168, 1118-1120 (1970).

Morrow, R. S.: Psychological aspects. Psychophysical and other functions. In: The Marijuana Problem in the City of New York, Lancaster, Pennsylvania: Jacques Cattel Press 1944 (Reprinted in: The Marihuana Papers, D. Solomon, ed. New York: Signet 1966).

Primary Mental Abilities Test. Chicago: Science Research Associates, Inc. 1962.

Rees, H. J., Israel, H. E.: An investigation of the establishment and operations of mental sets. Psychol. Monogr. 46, No. 6 (1934/35).

Rennick, P., Domino, E. F., Pearl, J.: Neuropsychological effects of marijuana smoking in experienced male users. In preparation (1973).

Thorndike, E. L., Lorge, I.: The teacher's word book of 30,000 words. New York: Teachers College, Columbia University, 1944.

Weil, A. T.: Marihuana effects amid great expectations. Science 165, 204 (1969).

Weil, A.T., Zinberg, N. E., Nelson, J. N.: Clinical and psychological effects of marihuana in man. Science 162, 1234-1242 (1968).

Werber, M., King, D. : An investigation of the response mechanism of the size weight illusion. J. gen. Psychol. 66, 85-100 (1962).

Witkin, H. A.: Individual differences in ease of perception of embedded figures. J. Personality 19, 1-15 (1950).

\author{
Dr. E. F. Domino \\ Laboratory of Pharmacology \\ Lafayette Clinic \\ 951 E. Lafayette \\ Detroit, Michigan 48207, U.S.A.
}

